\title{
Portopulmonary hypertension in cirrhotic patients: Prevalence, clinical features and risk factors
}

\author{
HUI-SONG CHEN, SU-RONG XING, WEI-GUO XU, FAN YANG, \\ XIAO-LONG QI, LE-MIN WANG* ${ }^{*}$ and CHANG-QING YANG* \\ Division of Gastroenterology and Digestive Diseases Institute, Tongji Hospital of \\ Tongji University School of Medicine, Shanghai 200065, P.R. China
}

Received November 12, 2012; Accepted January 11, 2013

DOI: $10.3892 /$ etm.2013.918

\begin{abstract}
The incidence and clinical features of portopulmonary hypertension (POPH) have not been adequately described and it is currently unknown whether an association exists between the severity of POPH and liver function. Additionally, POPH risk factors are yet to be identified. The aim of this study was to determine the prevalence, describe the clinical features and investigate the potential risk factors of POPH. We conducted a study of 100 cirrhotic patients hospitalized between March 2011 and May 2012 at Tongji Hospital in Shanghai. The clinical characteristics of patients with and without POPH were analyzed. Clinical variables with a possible association with POPH were measured and pulmonary artery systolic pressure (PASP) was determined by cardiac Doppler echocardiography. Of the 100 patients enrolled in this study, 10 were diagnosed with POPH. Seven of the cases were mild, two were moderate and only one was severe; eight were attributed to viral infections. POPH was not detected in patients with schistosomal or alcoholic cirrhosis. Hemoglobin $(\mathrm{Hb})$ levels were lower in patients with $\mathrm{POPH}$ compared to those without POPH $(\mathrm{P}<0.01)$ and the severity of POPH was not significantly correlated with Child-Pugh grade $(\mathrm{R}=-0.06, \mathrm{P}=0.09)$. Hb levels, incidence of hepatitis $\mathrm{C}$ virus $(\mathrm{HCV})$ infection and portal vein thrombosis differed between the two groups $(\mathrm{P}<0.05)$. Hb levels were identified as an independent risk factor associated with POPH and portal vein thrombosis may play an important role during the development of POPH. However, the severity of POPH was not associated with liver function.
\end{abstract}

Correspondence to: Professor Chang-Qing Yang, Division of Gastroenterology and Digestive Diseases Institute, Tongji Hospital of Tongji University School of Medicine, 389 Xincun Road, Putuo District, Shanghai 200065, P.R. China

E-mail: cqyang@tongji.edu.cn

*Contributed equally

Key words: liver cirrhosis, portopulmonary hypertension, risk factors, hemoglobin

\section{Introduction}

Portopulmonary hypertension (POPH) refers to the condition of simultaneous pulmonary arterial and portal hypertension. Hemodynamically, it is defined as a mean pulmonary artery pressure (MPAP) $>25 \mathrm{mmHg}$ and normal volume status or pulmonary capillary wedge pressure $(\mathrm{PCWP})<15 \mathrm{mmHg}$ in patients with chronic liver disease and portal hypertension (1-3). POPH has been reported in $\sim 6-9 \%$ of patients with advanced liver disease, that are referred for liver transplants $(4,5)$. This variation in prevalence results from the different groups of cirrhotic patients studied and different diagnostic procedures used.

Clinical manifestations of portal hypertension typically precede those of pulmonary artery hypertension by 2-15 years. The most common symptoms of POPH include dyspnea upon exertion, syncope, chest pain, fatigue, hemoptysis and orthopnea. The presence of molecular markers is also likely, as one study supported the hypothesis that pulmonary vasculature may be exposed to either cytokines or excess circulating vasoconstrictors, including interleukin- 6 and endotoxin produced by the diseased liver (6). However, to date, the predictors of and biological mechanism responsible for the development of this complication remain unknown.

There are no known clinical factors that determine the risk of POPH in patients with advanced liver disease. Similarly, the mechanism for pulmonary vascular obliteration in patients with portal hypertension, characterized by systemic vasodilation remains unclear. It follows that the identification of patient characteristics associated with an increase or decrease in the probability of developing POPH may not only be clinically useful, but may also shed light on the etiology of this relatively common comorbidity of portal hypertension. Therefore, the aims of this study were to explore the clinical features of POPH and to identify risk factors associated with POPH in cirrhotic patients.

\section{Patients and methods}

Patients. From March 2011 to May 2012, 145 consecutive adult patients with cirrhosis (102 males, 43 females) from our hospital were enrolled in the study. The only inclusion criterion was the presence of clinical portal hypertension 
Table I. Demographic and clinical features of the ten cirrhotic patients with POPH.

\begin{tabular}{ccccccc}
\hline Case & Age (years) & Gender & Etiology & Child-Pugh class & PASP (mmHg) \\
\hline 1 & 82 & Female & HBV+HCV & A & 68 & Moderate \\
2 & 68 & Female & HBV & B & 63 & Moderate \\
3 & 79 & Male & HCV & C & Mild \\
4 & 77 & Male & Autoimmune & B & Severe \\
5 & 82 & Female & HBV & C & 41 & Mild \\
6 & 76 & Male & HBV & C & 43 & Mild \\
7 & 30 & Male & HCV & B & Mild \\
8 & 62 & Female & HBV & B & Mild \\
9 & 72 & Female & Cryptogenic & B & 41 & Mild \\
10 & 36 & Male & HBV & Mild \\
\hline
\end{tabular}

POPH, portopulmonary hypertension; PASP, pulmonary artery systolic pressure; HBV, hepatitis B virus; HCV, hepatitis C virus.

Table II. Comparison of the clinical characteristics between cirrhotic patients with and without POPH.

\begin{tabular}{|c|c|c|c|c|}
\hline & POPH & Non-POPH & $t / \chi^{2}$ & P-value \\
\hline $\mathrm{N}$ & $10(10 \%)$ & $90(90 \%)$ & & \\
\hline Age (years) & $66.0 \pm 18.0$ & $61.6 \pm 13.9$ & 0.19 & 0.86 \\
\hline Gender (male/female) & $5 / 5$ & $65 / 25$ & 2.15 & 0.15 \\
\hline \multicolumn{5}{|l|}{ Etiology } \\
\hline HBV & $5(50 \%)$ & $51(56.7 \%)$ & 0.10 & 0.72 \\
\hline $\mathrm{HCV}$ & $2(20 \%)$ & $1(1.1 \%)$ & Fisher's exact test & 0.03 \\
\hline Alcoholic & $0(0 \%)$ & $5(5.6 \%)$ & Fisher's exact test & 1.00 \\
\hline Schistosomal & $0(0 \%)$ & $7(7.8 \%)$ & 0.07 & 0.79 \\
\hline Autoimmune & $1(10 \%)$ & $8(8.9 \%)$ & 0.01 & 0.91 \\
\hline Cryptogenic & $1(10 \%)$ & $18(20 \%)$ & 0.59 & 0.44 \\
\hline $\mathrm{HBV}+\mathrm{HCV}$ & $1(10 \%)$ & $0(0 \%)$ & Fisher's exact test & 0.10 \\
\hline \multicolumn{5}{|l|}{ Child-Pugh class } \\
\hline A & 1 & 13 & & \\
\hline $\mathrm{B}$ & 6 & 56 & 0.55 & 0.76 \\
\hline $\mathrm{C}$ & 3 & 21 & & \\
\hline \multicolumn{5}{|l|}{ Severity of POPH } \\
\hline Mild & 7 & 0 & & \\
\hline Moderate & 2 & 0 & & \\
\hline Severe & 1 & 0 & & \\
\hline
\end{tabular}

Age is expressed as mean \pm standard deviation (SD) and categorical variables are displayed as frequencies (\%). POPH, portopulmonary hypertension; HBV, hepatitis B virus; $\mathrm{HCV}$, hepatitis $\mathrm{C}$ virus.

with intrinsic liver cirrhosis. Patients with significant obstructive lung disease, restrictive ventilatory defects, human immunodeficiency virus, severe aortic or mitral stenosis, regurgitation or significant left ventricular dysfunction were excluded. Also excluded were individuals with hepatocellular carcinoma or any other malignancy, known hemostatic disorders other than liver disease, bacterial infection, a clinical history of peripheral venous thrombosis or Budd-Chiari syndrome, spleen resection, lung and liver transplantation and those receiving endoscopic treatment or anticoagulation therapy. A total of 100 patients were considered acceptable and were enrolled in our study. Informed consent was obtained from all patients and the study was carried out according to the principles of the declaration of Helsinki and the guidelines of the institutional ethics committee.

Liver cirrhosis was diagnosed by clinical findings or morphology and liver function of the POPH patients was scored using the Child-Pugh classification (7). Past medical history and social history were recorded. Non-invasive screening for POPH was performed and evaluated by Doppler echocardiog- 
Table III. Comparison of medical histories between patients with and without POPH.

\begin{tabular}{|c|c|c|c|c|}
\hline Variable & POPH (\%) & Non-POPH (\%) & $\chi^{2}$ & P-value \\
\hline $\mathrm{N}$ & 10 & 90 & & \\
\hline GI hemorrhage & 50 & 27.8 & 2.12 & 0.15 \\
\hline Hepatic encephalopathy & 20 & 23.3 & 0.06 & 0.81 \\
\hline Hepatorenal syndrome & 20 & 21.1 & 0.01 & 0.94 \\
\hline Ascites & 80 & 77.8 & 0.03 & 0.87 \\
\hline Smoking & 20 & 23.3 & 0.06 & 0.81 \\
\hline Alcohol abuse & 10 & 10.0 & 0.00 & 1.00 \\
\hline High blood pressure & 20 & 26.7 & 0.21 & 0.65 \\
\hline Diabetes mellitus & 10 & 11.1 & 0.01 & 0.92 \\
\hline Coronary artery disease & 10 & 5.6 & 0.32 & 0.58 \\
\hline Blood transfusion & 60 & 51.1 & 0.29 & 0.59 \\
\hline Portal vein thromosis & 50 & 16.7 & 5.63 & 0.04 \\
\hline Drug use & 10 & 0.0 & Fisher's exact test & $0.10^{\mathrm{a}}$ \\
\hline
\end{tabular}

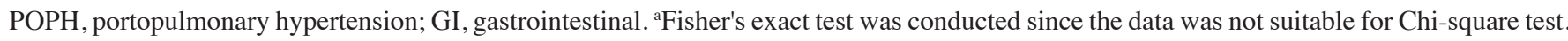

Table IV. Comparison of laboratory results between patients with and without POPH.

\begin{tabular}{lccrc}
\hline Variable & POPH & Non-POPH & $\mathrm{t}$ & P-value \\
\hline $\mathrm{Hb}(\mathrm{g} / \mathrm{l})$ & $72.6 \pm 14.2$ & $98.6 \pm 24.1$ & 2.46 & 0.00 \\
$\mathrm{BPC}\left(\mathrm{x} 10^{9} / \mathrm{l}\right)$ & $82.1 \pm 44.3$ & $83.4 \pm 46.9$ & -0.08 & 0.93 \\
TBIL $(\mu \mathrm{mol} / \mathrm{l})$ & $30.1 \pm 12.3$ & $40.8 \pm 25.4$ & 1.38 & 0.17 \\
ALB $(\mathrm{g} / \mathrm{l})$ & $26.1 \pm 5.5$ & $26.8 \pm 6.1$ & 0.33 & 0.75 \\
Hs-CRP $(\mathrm{mg} / \mathrm{l})$ & $9.8 \pm 9.0$ & $17.1 \pm 2.4$ & 0.93 & 0.36 \\
D-dimer $(\mathrm{mg} / \mathrm{l})$ & $0.3 \pm 0.2$ & $0.6 \pm 0.1$ & 1.09 & 0.28 \\
APTT $(\mathrm{sec})$ & $39.3 \pm 9.2$ & $36.6 \pm 10.4$ & -0.79 & 0.43 \\
PT $(\mathrm{sec})$ & $14.7 \pm 2.8$ & $14.1 \pm 2.9$ & -0.61 & 0.54 \\
TT $(\mathrm{sec})$ & $18.7 \pm 2.2$ & $21.2 \pm 5.1$ & 1.45 & 0.14 \\
Fibrinogen $(\mathrm{g} / \mathrm{l})$ & $2.4 \pm 0.7$ & $2.8 \pm 0.3$ & 0.40 & 0.69 \\
ICAM-1 $(\mathrm{ng} / \mathrm{ml})$ & $14.9 \pm 10.1$ & $19.3 \pm 2.5$ & 0.54 & 0.59 \\
IFN- $\alpha(\mathrm{pg} / \mathrm{ml})$ & $23.0 \pm 13.7$ & $37.4 \pm 16.6$ & 0.68 & 0.50 \\
TNF- $\alpha(\mathrm{pg} / \mathrm{ml})$ & $14.5 \pm 4.7$ & $21.3 \pm 3.2$ & 0.66 & 0.51 \\
\hline
\end{tabular}

Data are presented as mean \pm standard deviation $(\mathrm{SD})$. POPH, portopulmonary hypertension; $\mathrm{Hb}$, hemoglobin; $\mathrm{BPC}$, blood platelet count; TBIL, total bilirubin; ALB, albumin; hs-CRP, high sensitivity C-reactive protein; APTT, activated partial prothrombin time; PT, prothrombin time; TT, thrombin time; ICAM-1, intercellular adhesion molecule 1; IFN, interferon; TNF, tumor necrosis factor.

raphy. In order to identify risk factors associated with $\mathrm{POPH}$, the patients were classified into two groups: a POPH group [pulmonary artery systolic pressure (PASP) $\geq 40 \mathrm{mmHg}$ ] and a non-POPH group (PASP $<40 \mathrm{mmHg})(8,9)$.

Diagnosis of POPH. Pulmonary vascular resistance (PVR) is considered an essential feature of POPH. Diagnostic measurements of PVR are traditionally obtained by right heart catheterization (RHC) $(10,11)$; however, since bleeding complications are a concern among cirrhotic patients, other forms of diagnosis are preferred. Results of Doppler echocardiography are comparable to $\mathrm{RHC}$ in non-cirrhotic patients with pulmonary hypertension $(12,13)$. For cirrhotic patients undergoing liver transplantation $(14,15)$, it decreases the requirement for repeated invasive measurements. In our study, PASP (measured by Doppler echocardiography) was used to diagnose POPH.

Noninvasive color Doppler echocardiographies were performed on all patients. The MPAP was calculated from PASP $(\mathrm{MPAP}=0.61 \mathrm{PASP}+2 \mathrm{mmHg}$ ). PASP values of 38-54 mmHg were considered to represent mild POPH, 55-69 $\mathrm{mmHg}$ were moderate and values $\geq 70 \mathrm{mmHg}$ were severe (16).

Collection and analysis of blood samples. Blood samples $(20 \mathrm{ml})$ were collected from patients following at least $12 \mathrm{~h}$ of fasting. Hemoglobin ( $\mathrm{Hb}$ ) and blood platelet count (BPC) were determined using a Sysmex XE-2100 automated analyzer (Sysmex, Kobe, Japan). Total bilirubin (TBIL) and albumin (ALB) were determined using diazotization and the bromocresol green (BCG) assay method, respectively (Roche Cobas-c702, Germany). D-dimer and high sensitivity C-reactive protein (hs-CRP) levels were detected using the corresponding kits from Sun Biotech Co., Ltd. (Shanghai, China), following the manufacturer's instructions. Prothrombin time (PT), activated partial prothrombin time (APTT) and fibrinogen (Fib) were determined by routine coagulation methods with a coagulation detector, using a Sysmex CA-6000 automated analyzer (Sysmex, Milton Keynes, UK). Intercellular adhesion molecule 1 (ICAM-1), interferon- $\alpha$ (IFN- $\alpha$ ) and tumor necrosis factor- $\alpha$ (TNF- $\alpha$ ) were measured by enzyme-linked immunosorbent assay (ELISA).

Statistical analysis. The SPSS software package for Windows (SPSS version 11.0, SPSS Inc., Chicago, IL, USA) was used for statistical analysis. Continuous data were summarized using mean \pm standard deviation (SD) or median (interquartile 
Table V. Results of backward, stepwise logistic regression analysis of the correlation between POPH and Hb level, HCV, D-dimer level and portal vein thrombosis.

\begin{tabular}{lcccccc}
\hline Variables & $\beta$-value & SE & Wald value & P-value & OR & $95 \%$ CI \\
\hline $\mathrm{Hb}$ & -0.049 & 0.021 & 5.478 & 0.02 & 0.952 & $0.913-0.992$ \\
$\mathrm{HCV}$ & 2.464 & 1.787 & 1.901 & 0.17 & 11.746 & $0.354-389.915$ \\
$\mathrm{D}-\mathrm{D}$ & -0.020 & 0.025 & 0.625 & 0.43 & 0.981 & $0.934-1.0290$ \\
$\mathrm{PVT}$ & 1.129 & 0.778 & 2.296 & 0.13 & 3.252 & $0.707-14.949$ \\
\hline
\end{tabular}

POPH, portopulmonary hypertension; SE, standard error; OR, odds ratio; CI, confidence interval; Hb, hemoglobin; D-D, D-dimer; PVT, portal vein thrombosis.

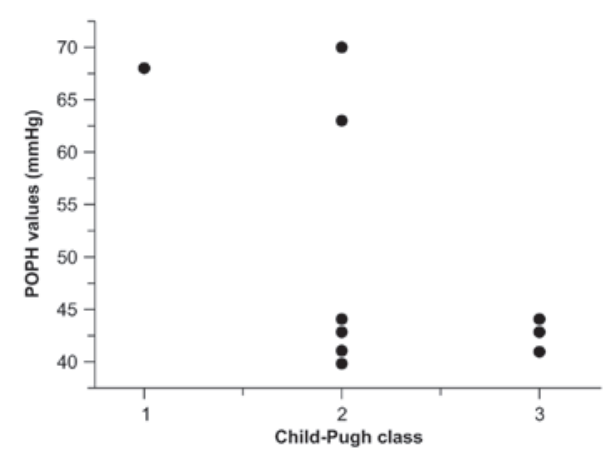

Figure 1. Correlation between Child-Pugh class and POPH values. The $\mathrm{X}$-axis represents the Child-Pugh grades of the POPH patients (1, class A; 2 , class $B$ and 3 , class $C$ ). The $y$-axis represents the determined POPH values of the $\mathrm{POPH}$ patients. Correlation analysis revealed that $\mathrm{POPH}$ values were not significantly correlated with Child-Pugh class $(\mathrm{R}=-0.06, \mathrm{P}=0.09)$. $\mathrm{POPH}$, portopulmonary hypertension.

range), as appropriate. Categorical variables were displayed as frequencies. Statistical analysis was performed using the appropriate parametric or non-parametric tests. Differences between the POPH and non-POPH groups were evaluated by Chi-square test. For continuous data, the assumption of normality was evaluated using a normality test. The Pearson Chi-square test, corrected Chi-square test and Fisher's exact test were used, as appropriate. Multivariate binary logistic regression was performed to evaluate the correlation between the presence of portal vein thrombosis and thrombotic risk factors with respect to the odds of occurrence for an event. The model was estimated using a backward stepwise method (Wald). In this multivariate analysis, we used a number of variables, including those that were not significant univariate predictors, since they may contribute to a multiple regression model in unforeseen ways due to complex intercorrelations among them. The coefficients obtained from the logistic regression analyses were also expressed in terms of odds ratios (ORs) with 95\% confidence intervals. Considering the number of cases, we determined that the final multivariate model should include $\leq 4$ predictors to prevent overfitting. A two-tailed P-value $\leq 0.05$ was considered to indicate a statistically significant difference.

\section{Results}

Clinical features. Ten of the 100 study patients (10\%) were diagnosed with POPH. Five of these $(50 \%)$ were males aged
30-79 years (bivariate correlation analysis was used) with a mean age of $59.0 \pm 24.0$ years. Five $(50 \%)$ were females aged 62-82 years, with a mean age of $73.0 \pm 9.0$ years. The median age of the $10 \mathrm{POPH}$ patients was 66 years. With regard to the etiology of subjects, eight of the POPH patients had viral cirrhosis [hepatitis B virus (HBV), hepatitis C virus (HCV) or $\mathrm{HBV}$ and $\mathrm{HCV}]$, one had autoimmune cirrhosis and one had cryptogenic cirrhosis. POPH was not observed in schistosomal or alcoholic cirrhosis patients. Among the ten POPH patients, PASP values were $40-70 \mathrm{mmHg}$. The severity of POPH in the subjects is listed in Table I.

Clinical symptoms or signs. The presentations of the decompensate liver cirrhosis and portal hypertension, including jaundice, ascites, splenomegaly, edema and gastrointestinal hemorrhage were observed in the cirrhotic patients with POPH. Although a number of patients with POPH are asymptomatic (17), other POPH patients presented with syndromes and signs of pulmonary hypertension. Two patients presented dyspnea upon exertion, two with syncope, one with chest pain and one with hemoptysis.

Risk factors analysis. There were no significant differences in age or gender between the POPH and the non-POPH groups (mean age, $66.0 \pm 18.0$ vs. $61.6 \pm 13.9$ years; $\mathrm{P}=0.86, \mathrm{P}=0.15$, respectively). Of the etiologies studied, only the prevalence of HCV-related cirrhosis patients differed between the two groups $(\mathrm{P}=0.001)$. With regards to liver function, we identified that one $\mathrm{POPH}$ patient was Child-Pugh grade $\mathrm{A}$, six were grade $\mathrm{B}$ and three were grade $\mathrm{C}$. There were no significant differences in Child-Pugh grade between the two groups $(\mathrm{P}=0.76)$. With regard to the severity of $\mathrm{POPH}$, liver damage was mild in seven patients, moderate in two patients and severe in one patient. With respect to past medical history only the incidence of portal vein thrombosis differed significantly between the POPH and non-POPH groups $(\mathrm{P}=0.02$; Tables II and III).

The levels of BPC, ALB, TBIL, Hs-CRP, D-dimer, thrombin time (TT), Fib, ICAM-1, IFN- $\alpha$ and TFN- $\alpha$ did not differ significantly between POPH and non-POPH patients. There were no significant differences in the levels of APTT and PT between the two groups. However, the levels of $\mathrm{Hb}$ were lower in the POPH group than those in the non-POPH groups $(\mathrm{P}=0.001)$. Hb was determined to be a risk factor of $\mathrm{POPH}$ by univariate analysis (Table IV). 
Correlation between Child-Pugh class and severity of $P O P H$. In our study, a correlation between Child-Pugh class and severity of POPH (reflected by the value of PASP) was investigated. The results revealed that the PASP values were not significantly correlated with Child-Pugh class $(\mathrm{R}=-0.06$, $\mathrm{P}=0.09$; Fig. 1).

Multivariate analysis. The $\mathrm{Hb}, \mathrm{HCV}$, D-dimer and portal vein thrombosis were included in multivariate logistic regression analysis. Only $\mathrm{Hb}$ was identified as an independent factor associated with an increased risk of POPH (OR=0.952; Table V).

\section{Discussion}

In the present study, POPH was diagnosed in $10 \%$ of patients with cirrhosis. This is within the range of prevalence reported in the literature (20). In previous studies, POPH has been estimated to occur with a prevalence of $16.1 \%$ in patients with cirrhosis and refractory ascites and $0.25-4 \%$ in patients with cirrhosis without refractory ascites $(18,19)$.

Although our results demonstrated that there are higher percentages of females with cirrhosis that develop POPH, no significant difference was observed in the incidence of POPH across the gender (results not shown). This indicates that males and females with cirrhosis are at risk of developing POPH. These results contradict the findings of a previous study that identified that females are at a higher risk of POPH (11).

In our study, the majority of the POPH patients had viral cirrhosis (HBV and HCV). Viral cirrhosis was the most common type of cirrhosis among our Chinese population; however, our results demonstrated that a higher incidence of POPH exists among patients with viral cirrhosis. While previous research identified that HCV infection was negatively correlated with POPH (11), this was not supported by our data. In contrast, the high incidence of POPH among patients with $\mathrm{HCV}$ infection indicates that patients with HCV cirrhosis may be at higher risk of developing POPH.

With regard to the severity of $\mathrm{POPH}$, our results demonstrated that the severity of POPH is unrelated to liver function, as we were unable to identify an association between POPH severity and Child-Pugh class. However, this conclusion is based on a small number of cases and larger studies are required to verify this correlation.

Previously hypothesized risk factors of POPH were not associated with POPH in our study. Age, gender and ChildPugh class did not differ between the POPH and non-POPH groups. Also, hepatic complications, including GI hemorrhage, hepatorenal syndrome ascites and encephalopathy did not differ between the groups. Similarly, HBP, DM, coronary artery disease, drug use and blood transfusion did not appear to affect the risk of developing POPH and smoking and alcohol use were common in the two groups.

With respect to patient medical histories, only portal vein thrombosis differed between the two groups, indicating that portal vein thrombosis is associated with POPH. These results are supported by a previous study that described microembolism of the lungs in hepatic fibrosis due to recurrent cholangitis. The passage of small emboli to the lungs was attributed to the presence of small hepatic arteriovenous fistulae (21). The correlation between POPH and portal vein thrombosis may be explained by a similar anatomical mechanism. Portal venous obstruction secondary to portal vein thrombosis would likely enlarge such communications, resulting in repeated microembolism of the lungs. This may lead to pulmonary hypertension and, ultimately, congestive failure due to chronic cor pulmonale (21).

Among the laboratory parameters examined in our study, levels of $\mathrm{Hb}$ were lower in the $\mathrm{POPH}$ group than in the non-POPH group. To our knowledge, a correlation between $\mathrm{POPH}$ and $\mathrm{Hb}$ has not been described previously. However, it is known that a decrease in $\mathrm{Hb}$ leads to a significant increase in cardiac output and exacerbated hyperdynamic splanchnic circulation (22). The hyperdynamic splanchnic circulation is a major contributor to portal hypertension. Therefore, it is not surprising that $\mathrm{Hb}$ levels were significantly lower in the POPH group and that $\mathrm{Hb}$ level was the only variable independently associated with POPH. These findings indicate that Hb level is an independent risk factor and plays a key role in the development of POPH. While HCV and PVT were also associated with a higher incidence of $\mathrm{POPH}$, these factors were not independent predictors of POPH. Perhaps they contributed to the formation of POPH through interactions with other unknown factors. However, significant differences between the two groups were not observed for any of the other markers that we investigated.

In conclusion, within our study population POPH was present in $10 \%$ of cirrhotic patients. It was most common among patients with viral cirrhosis and absent among schistosomal and alcoholic cirrhosis patients. Notably, the severity of POPH was unrelated to liver function (Child-Pugh classification). $\mathrm{HCV}$ infection and portal vein thrombosis may play important roles during the development of $\mathrm{POPH}$; however, $\mathrm{Hb}$ level is the only significant, independent predictor of POPH. Future studies should examine the mechanistic role of these factors in the development of POPH.

\section{Acknowledgements}

This study was supported by the Natural Science Foundation of China (81070343) and the Shanghai Excellent Academic Pacesetters Program (08xD14045)

\section{References}

1. Hadengue A, Benhayoun M, Lebrec D and Benhamou J: Pulmonary hypertension complicating portal hypertension: prevalence and relation to splanchnic hemodynamics. Gastroenterology 100: 520-528, 1991.

2. Simonneau G, Galič N, Rubin LJ, Langleben D, Seeger W, Domenighetti G, Gibbs S, Lebrec D, Speich R and Beghetti M: Clinical classification of pulmonary hypertension. J Am Coll Cardiol 43: S5-S12, 2004.

3. Krowka MJ: Hepatopulmonary syndrome versus portopulmonary hypertension: distinctions and dilemmas. Hepatology 25: 1282-1284, 1997.

4. Castro M, Krowka MJ, Schroeder DR, Beck KC, Plevak DJ, Rettke SR, Cortese DA and Wiesner RH: Frequency and clinical implications of increased pulmonary artery pressures in liver transplant patients. Mayo Clinic Proc 71: 543-551, 1996.

5. Kawut SM, Krowka MJ, Trotter JF, Roberts KE, Benza RL, Badesch DB, Taichman DB, Horn EM, Zacks S and Kaplowitz N: Clinical risk factors for portopulmonary hypertension. Hepatology 48: 196-203, 2008.

6. Kalambokis GN, Mouzaki A, Rodi M, Pappas K, Korantzopoulos P and Tsianos EV: Circulating endotoxin and interleukin-6 levels are associated with Doppler-evaluated pulmonary vascular resistance in cirrhotic patients. Hepatol Int 6: 783-789, 2012. 
7. Shetty K, Rybicki L and Carey WD: The Child-Pugh classification as a prognostic indicator for survival in primary sclerosing cholangitis. Hepatology 25: 1049-1053, 1997.

8. Cotton CL, Gandhi S, Vaitkus PT, Massad MG, Benedetti E, Mrtek RG and Wiley TE: Role of echocardiography in detecting portopulmonary hypertension in liver transplant candidates. Liver Transpl 8: 1051-1054, 2002.

9. Sciomer S, Magrì D and Badagliacca R: Non-invasive assessment of pulmonary hypertension: Doppler-echocardiography. Pulm Pharmacol Ther 20: 135-140, 2007.

10. Krowka MJ: Evolving dilemmas and management of portopulmonary hypertension. Semin Liver Dis 26: 265-272, 2006.

11. Golbin JM and Krowka MJ. Portopulmonary hypertension. Clin Chest Med 28: 203-218, 2007.

12. Scapellato F, Temporelli PL, Eleuteri E, Corrà U, Imparato A and Giannuzzi P: Accurate noninvasive estimation of pulmonary vascular resistance by Doppler echocardiography in patients with chronic heart failure. J Am Coll Cardiol 37: 1813-1819, 2001.

13. Abbas AE, Fortuin FD, Schiller NB, Appleton CP, Moreno CA and Lester SJ: A simple method for noninvasive estimation of pulmonary vascular resistance. J Am Coll Cardiol 41: 1021-1027, 2003.

14. Farzaneh-Far R, McKeown BH, Dang D, Roberts J, Schiller NB and Foster E: Accuracy of Doppler-estimated pulmonary vascular resistance in patients before liver transplantation. Am J Cardiol 101: 259-262, 2008.
15. Kim W, Krowka MJ, Plevak DJ, Lee J, Rettke SR, Frantz RP and Wiesner RH. Accuracy of Doppler echocardiography in the assessment of pulmonary hypertension in liver transplant candidates. Liver Transpl 6: 453-458, 2000.

16. Chemla D, Castelain V, Humbert M, Hébert JL, Simonneau G, Lecarpentier Y and Hervé P: New formula for predicting mean pulmonary artery pressure using systolic pulmonary artery pressure. Chest 126: 1313-1317, 2004.

17. Robalino BD and Moodie DS: Association between primary pulmonary hypertension and portal hypertension: analysis of its pathophysiology and clinical, laboratory and hemodynamic manifestations. J Am Coll Cardiol 17: 492-498, 1991.

18. Benjaminov F, Prentice M, Sniderman K, Siu S, Liu P and Wong F: Portopulmonary hypertension in decompensated cirrhosis with refractory ascites. Gut 52: 1355-1362, 2003.

19. Hoeper MM, Krowka MJ and Strassburg CP: Portopulmonary hypertension and hepatopulmonary syndrome. Lancet 363 : 1461-1468, 2004

20. Humbert M, Sitbon O, Chaouat A, Bertocchi M, Habib G, Gressin V, Yaici A, Weitzenblum E, Cordier JF and Chabot F: Pulmonary arterial hypertension in France. Am J Respir Crit Care Med 173: 1023-1030, 2006.

21. Lai K, McFadzean A and Yeung R: Microembolic pulmonary hypertension in pyogenic cholangitis. Br Med J 1: 22-24, 1968.

22. Groszmann RJ: Hyperdynamic circulation of liver disease 40 years later: pathophysiology and clinical consequences. Hepatology 20: 1359-1363, 1994. 